\title{
The Value of Risk in Real Estate Markets
}

\author{
DENNIS R. CAPOZZA \\ University of Michigan, Michigan Business School, Ann Arbor, MI 48109-1234 \\ GREGORY M. SCHWANN \\ Center for Real Estate and Urban Economics, University of California, Berkeley, CA 94720
}

\begin{abstract}
In this article we test the urban asset pricing model of Capozza and Sick (1988) and focus on the empirical dimensions of the effects of risk on urban land prices. The effects of systematic and unsystematic risk are distinguished in the model which incorporates the value of the option to convert land to urban uses into the pricing of urban real estate. We find the value of systematic risk in our Canadian urban areas to be negative and highly statistically significant. We find that approximately 2.5 percent of the value of houses in our sample arises from systematic risk. In our sample, unsystematic risk is a larger proportion of total risk than systematic risk. Therefore, most of the effect of total risk may be ascribed to unsystematic risk. The effect of total risk on land prices is illustrated through the irreversibility premia estimates. These premia vary greatly in size and statistical significance. Thus, the effect of unsystematic risk is highly city specific. In the two regions where the irreversibility premia are statistically significant, it accounts for 22 percent and 53 percent of the average housing price; thus, unsystematic risk can be a very important determinant of housing prices.

These results highlight the importance of risk in determining urban land prices. The value of the option to convert land to urban uses imparts considerable value to developed land and must be considered when evaluating interurban area price differences.
\end{abstract}

What determines the value of real estate within and between urban areas? Does risk affect real estate prices in urban areas? Should risk increase or decrease real estate prices? These are surprisingly difficult questions to answer, both theoretically and empirically, even though there is an extensive literature in finance on the role of risk in asset pricing. Indeed, our earlier empirical analysis (Capozza and Schwann, 1989) of an asset pricing model for real estate did not find a statistically significant relationship between housing prices and risk in 19 Canadian urban areas. ${ }^{1}$

This article examines the impact of risk on urban land prices by estimating an empirical model of land pricing based on the work of Capozza and Sick (1988). ${ }^{2}$ The Capozza-Sick model addresses the effects of both systematic and unsystematic risk on the prices of developed urban land and undeveloped (agricultural) land outside the urban area. In the model, rents are stochastic and developers choose the time to convert land from agricultural to urban use contingent upon the systematic and unsystematic risk in the expected rents. The impact of risk on real estate prices depends on the type of risk (systematic or unsystematic) and the location of the land (urban or undeveloped). Systematic or market risk has a negative effect on the price of urban land but an indefinite effect on the price of undeveloped land. ${ }^{3}$ Unsystematic or idiosyncratic risk has no direct effect on the price of 
urban land but has a positive effect on the price of undeveloped land and on the trigger or hurdle price for development. As a result, unsystematic risk indirectly raises average prices for a given size urban area.

Our empirical model is closely aligned to the theoretical work. The functional forms we use for the estimating equations are based directly upon those in the theoretical work, and we use the same structure for uncertainty as in the theoretical analysis. To preview the conclusions, we find that our sample of Canadian urban areas has a negative beta (systematic risk). We also find that unsystematic risk increases the hurdle price for development and that this increase is significant.

The article is organized into five sections. The first section summarizes the model. The second section describes our empirical model. The third discusses our data set. The fourth outlines the results and the final section concludes.

\section{The model}

The model is described completely in Capozza and Sick. Here we briefly outline the model and the method of solution.

\subsection{Geography}

A small, open urban area is located on a homogeneous plain, $2 \phi$ radians of which are suitable for development. Employment and production are concentrated at a point CBD (central business district) to which all households commute daily. Locations are indexed by their distance $z$ from the CBD, where distance is measured so that it costs $\$ 1$ to commute a unit distance. The boundary of the urban area at time $t$ is denoted by $z^{*}(t)$.

\subsection{Household equilibrium}

We assume that at each time $t \in[0, \infty)$ households derive their utility from the consumption of land and a composite, numeraire good $x(t)$. In addition, all households are identical in the sense that no other factors affect household utility. It is further assumed that each household rents exactly one unit of land. Under these assumptions, locational equilibrium for the household implies the bid-rent function for land

$$
R(z, t)=R(0, t)-z
$$

\subsection{The nature of uncertainty}

We assume that rent follows the normal diffusion process with drift $^{4}$ given by ${ }^{5}$

$$
d R=g d t+\sigma d B(t)
$$


In equation (2), $g$ and $\sigma^{2}$ are the constant drift and variance of the process and $B(t)$ is a standard Brownian motion. ${ }^{6}$ Although $R(z, t)$ depends on time and location, $g$ and $\sigma$ are assumed to be independent of $z$ and $t$.

We assume that investors have homogeneous beliefs and model consistent (i.e., rational) expectations with respect to the parameters of the process. In this case, $g$ can be viewed as the expected growth, and $\sigma^{2}$ may be viewed as the spread of prices around the trend. The latter term can be decomposed into components reflecting systematic and unsystematic risk according to

$$
\sigma d B(t)=b d f(t)+d h(t)
$$

where $f(t)=\sigma_{f} B_{f}(t), h(t)=\sigma_{h} B_{h}(t)$, and $B_{f}$ and $B_{h}$ are independent Brownian motion processes. Here $f(t)$ denotes the systematic risk and $h(t)$ denotes the unsystematic risk. The coefficient $b$ measures the market risk of the rent fluctuations and we will call it the "rent beta." It follows from the independence and Brownian (i.e., normal) nature of the processes $B_{f}$ and $B_{h}$ that the aggregate process $B$ has variance

$$
\sigma^{2}=b^{2} \sigma_{f}^{2}+\sigma_{h}^{2}
$$

Hence, the variance of the rent process consists of a component related to market risk and a component related to unsystematic risk.

\subsection{The value of urban land}

Landowners know the current rent $R(t)$. Also, because they have model consistent expectations, they know $g$ and $\sigma$ and, hence, the distribution of future rents. With this information, they are able to determine the certainty equivalent price of the uncertain future rent $R(\tau)$, received at time $\tau>t$. Let $C E_{t}(R(\tau) \mid R(t))$ signify this certainty equivalent price. Using equations (2) and (3), the certainty equivalent rent is given by

$$
\begin{aligned}
C E_{t}(R(\tau)) & =E[R(\tau) \mid R(t)]-\lambda b(\tau-t) \\
& =R(t)+g(\tau-t)-\lambda b(\tau-t)
\end{aligned}
$$

where $\lambda$ is the market price of risk. The interest rate, $r$, is a real rate of interest and is assumed to be constant.

The (asset) price of urban land is the discounted value of the stream of certainty equivalent rents from the date land is converted from agricultural to urban use, $t^{*}$, onward. That is,

$$
P(t)=\int_{t}^{\infty} C E_{t}(R(\tau) \mid R(t)) e^{-r(\tau-t)} d \tau, \quad t \in\left[t^{*}, \infty\right)
$$

Together, equations (5) and (6) imply that the price of urban land can be written as 


$$
\begin{aligned}
P(t) & =\int_{t^{*}}^{\infty}[R(t)+g s-\lambda b s] e^{-r s} d s \\
& =\frac{R(t)}{r}+\frac{g}{r^{2}}-\frac{\lambda b}{r^{2}} \\
& =\frac{R(0)}{r}+\frac{g t}{r}+\frac{g-\lambda b}{r^{2}} .
\end{aligned}
$$

\subsection{The value of agricultural land}

Land in agricultural use earns riskless real rent $A$. Some agricultural land may be prohibited from conversion to urban use for such reasons as great distance from an urban area or inclusion in an agricultural land reserve. This land is pure agricultural land. It has value at time $t$

$$
P^{p a}=\int_{t}^{\infty} A e^{-(\tau-t)} d \tau=A / r
$$

Thus, pure agricultural land can be viewed as a consol bond. Agricultural land which can be converted to urban uses is assumed to be converted at a constant unit cost $C$. Once converted, this land commands the uncertain urban rent $R(t)$. The value of this convertible agricultural land is

$$
\begin{aligned}
\mathrm{P}^{\mathrm{a}}(t) & =A / r+W(\mathrm{P}(t)) \\
& =P^{p a}+W(P(t))
\end{aligned}
$$

where $W(P(t))$ is the value of a perpetual American call option or warrant on urban land with an exercise price of $A / r+C$.

The owner of the agricultural land will choose the date of conversion, $t *$, to maximize the value of the land.

\subsection{Solution}

Solution of the model is described in Appendix B. Here we note the key results. ${ }^{7}$

The value of the option to convert is given by

$$
W(P(t))=\frac{1}{\alpha r} e^{-\alpha r(P *-P)}
$$

and hurdle price, $P^{*}$, at which development occurs is 


$$
P^{*}=A / r+C+\frac{\hat{g}}{r^{2}}+\frac{r-\alpha \hat{g}}{\alpha r^{2}}
$$

where

$$
\alpha=\frac{\left[\hat{g}^{2}+2 r \sigma^{2}\right]^{1 / 2}-\hat{g}}{\sigma^{2}}
$$

and $\hat{g}=g-\lambda b$ is the risk-adjusted growth rate. From equation (11) it can be seen that the hurdle price $P^{*}$ is composed of four items: (1) the value of pure agricultural land, $A / r$; (2) the cost of conversion, $C$; (3) a growth premium, $\hat{g} / r^{2}$; and (4) an irreversibility term, $(r-\alpha \hat{g}) /\left(\alpha r^{2}\right)$. Since developers do not leapfrog in development, conversion occurs at the edge of the city. Therefore, $P^{*}$ is the hurdle price at the edge of the city. Land prices in the interior of the city equal $P^{*}$ plus the location premium $\left(z^{*}-z\right) / r$. Hence, the value of urban land is

$$
P(t)=A / r+C+\hat{g} / r^{2}+\frac{r-\alpha \hat{g}}{\alpha r^{2}}+(1 / r)\left(z^{*}-z\right), z \leq z^{*}
$$

The value of the agricultural land is

$$
P^{a}(t)=\frac{A}{r}+\frac{\hat{g}}{r^{2}} e^{-\alpha\left(z-z^{*}\right)}+\frac{r-\alpha \hat{g}}{\alpha r^{2}} e^{-\alpha\left(z-z^{*}\right)}, z \geq z^{*}
$$

The first term here is the value of pure agricultural land; the second and third are, respectively, the risk-adjusted growth and irreversibility premia. ${ }^{8}$ The coefficient $e^{-\alpha\left(z-z^{*}\right)}$ in the expressions for each premium is a locational discount factor. It indicates that these premia decay exponentially at the rate $\alpha$ with distance from the edge of the city.

The decompositions of equations (14) and (13) are illustrated in figure 1.

Although the model we have presented is highly simplified, it should be noted that the basic structure of the urban area as illustrated in figure 1 holds when the model is extended in a number of directions. For example, models with a log-normal diffusion (Capozza and Sick, 1988), with variable density (Capozza and Li, 1989), and with property taxes (Capozza and $\mathrm{Li}, 1989$ ) produce similar urban structural equations. Also, the option value of land in this article is related to the option value of financial securities. The seminal Black-Scholes option pricing model for financial securities has withstood numerous extensions without fundamental alteration. ${ }^{9}$ These extensions include nonconstant interest rates and nonconstant variance, alternative stochastic processes, and numerous modifications of the contract terms. While these extensions do affect the quantitative results, the qualitative results are usually similar to those for the original Black-Scholes model. Therefore, we conjecture that the description of urban land pricing illustrated in figure 1 is likely to be robust to a wide variety of extensions and modifications which as yet have not been explored. Most of these extensions will require numerical solutions since the differential equation at the core of the model quickly becomes unsolvable under modification. 


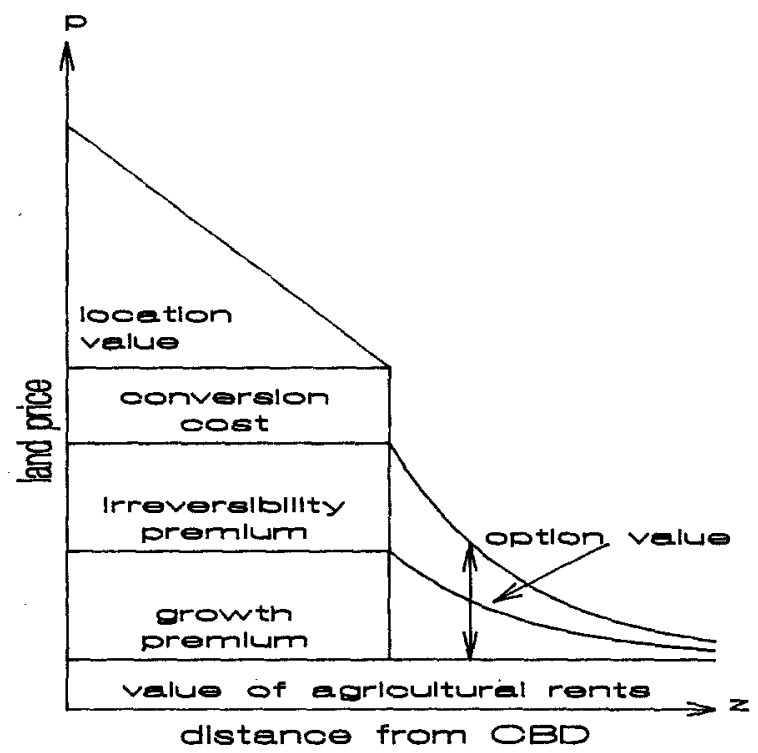

Fig. 1. Land prices inside and outside the urban area.

\section{The empirical model}

In this section we convert the continuous time model of urban land pricing outlined in the preceding section into an estimable econometric model. This involves some simplifications, but we have tried to stay as close to the theoretical model as our data allow. By building a tight model, we endogenize the determination of risk and thereby avoid the risk measurement problem. In addition, a tight model allows theory to speak with a stronger voice, putting it on a more equal footing with the data. Of course, we recognize that the flip side of using a model with little slippage is that it may lack realism in some respects.

We begin our modelling by letting $p_{t}$ be the price corresponding to realization of the normal diffusion process for rents in equation (2) and letting $p_{t}{ }^{*}$ be the hurdle price at the corresponding time. One property of normal diffusion processes is that for any interval of time $s>0$ the difference in prices $p_{t+s}-p_{t}$ is normally distributed about its mean with variance $\sigma^{2}\left(s / r^{2}\right)$. In our application, the mean of the difference in prices $p_{t}-p_{0}$ is given by equation (7) where $p_{0}=R_{0} / r$. By holding $p_{0}$ fixed, letting $s=1,2, \ldots$ years, and adding an error term, we obtain the following empirical version of equation (7).10

$$
\begin{aligned}
p_{t} & =p_{0}+(g-\lambda b)\left(1 / r_{t}^{2}\right)+g\left(t / r_{t}\right)+\epsilon_{1 t} \\
& =p_{0}+g\left(t / r_{t}+1 / r_{t}^{2}\right)-\lambda b\left(1 / r_{t}^{2}\right)+\epsilon_{1 t} .
\end{aligned}
$$

We use this equation as our basic estimating equation for land prices. The errors, $\epsilon_{1 t}$, are assumed to be independent and normally distributed with mean zero and variance $\sigma_{1}^{2}\left(t / r_{t}^{2}\right)$. 
This specification for the errors follows from the underlying theoretical model. We note that equation (15) departs from its theoretical counterpart (7) by introducing a variable interest rate.

Equation (15) contains four estimable parameters: $p_{0}, g, \lambda b$, and the equation variance $\sigma_{1}^{2}$. We cannot separate the price of risk, $\lambda$, and the rent beta, $b$, nor can we identify the separate contributions of systematic and unsystematic risk to the total variance in land prices. However, we note that theoretical consistency requires that the variance of systematic risk not vanish. If it vanishes, the rent beta has no meaning, and the $\lambda b$ term should be dropped from equation (15).

The estimation of equation (15) looks like a straightforward weighted least-squares problem. This is not the case. The model of land pricing described above implies that the distribution of observed prices is truncated from below. The truncation occurs because the price of a parcel of land, $p_{t}$, is observed only if it equals or exceeds the hurdle price for conversion $p_{t}^{*}$. When this is the case, the parcel is converted from agricultural to urban use, and the sale price of the parcel is recorded as it passes from the hands of the developer to the end user. If $p_{t}<p_{t}^{*}$, the land is not converted, no sale takes place, and $p_{t}$ is unobserved.

Because of the truncation, ordinary least squares (OLS) or reweighted least squares (WLS) estimates of the parameters of equation (15) will be inconsistent. To obtain consistent estimates of the parameters, a hurdle price equation must be specified and system of equations estimated by maximum likelihood. The following subsection examines the specification of the hurdle price equation. The likelihood function is presented in section 2.2.

\subsection{Hurdle prices}

We follow our theory as closely as possible in specifying a hurdle price equation. The equation we use is based on equation (14). It is:

$$
p_{t}^{*}=\beta_{0}+\beta_{1} c_{t}+1 /\left(\alpha_{t} r_{t}\right)+\left(z_{t}^{*}-z_{t}\right) / r_{t}
$$

where the form of $\alpha_{t}$ is given by equation (12). Agricultural land rents are omitted from equation (16) because there are no data. ${ }^{11}$ Also missing from our data set is the location of construction, $z_{t}$, and direct measurements on the distance to the city boundary, $z_{t}^{*}$. These omissions present more serious problems than the lack of agricultural land rent data. The consequences of these missing data are examined in the remainder of this section under various assumptions, together with our strategy for dealing with the problem.

Consider first dropping $z_{t}$ from equation (16), but retaining some estimate of $z_{t}^{*}$. This is a wholly unsatisfactory solution, since it implies that all construction takes place in the CBD. We therefore discard it.

A more acceptable solution is to ignore the entire location rent term $z_{t}^{*}-z_{t}$. This implies that all construction takes place at the edge of the city. Since much construction is near city boundaries, dropping $z_{t}^{*}-z_{t}$ does more limited violence to reality. Nevertheless, this is a strong assumption. In a world with construction lags ${ }^{12}$ and cities with heterogeneous parcels of land, any sample taken at a point in time will contain structures 
under construction at various sites within the city. However, it is reasonable to assume that the distribution of construction sites is concentrated near the edge of the city and that the spread of the distribution is positively related to city size. Our approach to modelling locational rent is based upon these conjectures.

Our first step is treat the unknown mean location of construction in period $t, z_{t}$, as a random variable. It is clear from the outset that $z_{t}$ cannot be fixed. It will increase if the city grows and decrease if the city shrinks. We capture this dependence on city size, simply, by assuming that $z_{t}$ is proportional to city size with the constant of proportionality $\delta$. Under this assumption, the mean locational rent is

$$
E\left(z_{t}^{*}-z_{t}\right)=(1-\delta) E\left(z_{t}^{*}\right)
$$

When $\delta=1$, construction takes place at the city boundary; when $0 \leq \delta<1$, the average construction site is in the interior of the city.

The actual location rents of buildings under construction will vary around equation (17) as the location of construction varies around $\delta E\left(z_{t}^{*}\right)$. This has two effects on our analysis. First, it introduces a random ${ }^{13}$ element to the hurdle price, and second, it means that the variance of location rents plays a role in estimation.

Our intuition suggests that the variance of $z_{t}$ should depend on city size. The larger the city, the greater is the potential spread in construction locations. Thus, the error term in the hurdle price equation is heteroscedastic. A plausible formulation for the variance of construction locations is:

$$
\sigma_{z t}^{2}=\gamma_{0}+\gamma_{1} z_{t}^{*}+\gamma_{2} z_{t}^{2}
$$

The linear and quadratic terms capture the desired effect of city size upon the spread of construction. If both $\gamma_{1}$ and $\gamma_{2}$ equal zero, then all cities are equally spread out in terms of construction. The quadratic term is included to accommodate nonlinear effects that may arise from including urban areas of widely varying sizes in our cross-sectional data set.

The second and final step in specifying the location rent (17) is to specify the city boundary, $z_{t}^{*}$. Here theory aids us. We know that the boundary of a city with $h$ households and $2 \phi$ radians of developable land is $z^{*}=(h / \phi)^{1 / 2}$. This equation gives a functional form for the city boundary. Moreover, since the number of households in each city is observable, all that remains to specify is $\phi$, the percentage of developable land in each annulus. We do so now.

In the long run, the developable land area of a city of fixed radius is set by its geographic and topographic characteristics. Thus, for each city the long-run value $\phi$ is fixed exogenously and, hence, may be captured by a dummy variable. Unfortunately, attempts to include dummies for $\phi$ had to be abandoned because of the collinearity of these dummies with the city dummies used to proxy agricultural land rent levels. ${ }^{14}$ When there is short-run slack in a city's housing markets, the fraction of land developed at the edge of the city may fall considerably below potential. To capture these short-run fluctuations in $\phi$ we include two variables measuring housing market slack: the vacancy rate in apartments of six units or more and the ratio of current starts to a two-year moving average of past starts. ${ }^{15}$ The apartment vacancy rate is a direct measure of excess capacity or slack. Of course, its limitation 
is that it addresses only one segment of the housing market. The starts variable reflects general demand conditions in the housing market. An increase in starts above the norm implies excess demand for housing which, in turn, implies an excess demand for developable land. Expressing the starts variable as a fraction of past starts removes the unwanted city size dimension of starts.

We combine the number of households, $h_{t}$, the apartment vacancy rate, $v_{t}$, and the starts measure, $s_{t}$, to determine $z_{t}^{*}$ in the following manner:

$$
z_{t}^{*}=\psi_{0} k\left(\psi_{1} v_{t}+\psi_{2} s_{t}\right) h_{t}^{1 / 2}
$$

In our estimation we take $k(\cdot)$ to be $1 / 2(\sin (\cdot)+1)$, which constrains $k \in[0,1]$ and $z_{i}^{*}$ to be nonnegative. The value of $k$ may be interpreted as the proportion of developable land currently under development. Our preceding arguments indicate that $\psi_{1}$ should be negative and $\psi_{2}$ should be positive.

Substituting equation (19) into (17) gives the mean location rent for properties under construction. Combining the resulting expression with (16), we get the empirical hurdle price equation

$$
p_{t}^{*}=\beta_{0}+\beta_{1} c_{t}+1 /\left(\alpha_{t} r_{t}\right)+(1-\delta) \psi_{0} k\left(\psi_{1} v_{t}+\psi_{2} s_{t}\right) h_{t}^{1 / 2} / r_{t}+\epsilon_{2 t}
$$

where $\epsilon_{2 t}$ has mean zero and variance $\sigma_{2 t}^{2} / r_{t}^{2}$. In equation (20), both $\delta$ and $\psi_{0}$ serve to scale the city boundary; thus, only one of them can be identified. The identifying restriction $\psi_{0}=1$ is used in estimation.

\subsection{The log likelihood function}

The model described by the land price equation (15) and the hurdle price equation (20) may be written more succinctly as:

$$
\begin{aligned}
& p_{t}=f^{1}\left(x_{1 t}\right)+\epsilon_{1 t} \\
& p_{t}^{*}=f^{2}\left(x_{2 t}\right)+\epsilon_{2 t}
\end{aligned}
$$

where $p_{t}$ is observed only if $p_{t} \geq p_{t}^{*}$. This system constitutes a truncated regression model which must be estimated by maximum likelihood. The likelihood for equation (21) is well known (see, for example, Maddala, 1983, ch. 6). However, before specifying the likelihood for this application, we perform some convenient transformations of variables.

Both errors, $\epsilon_{1 t}$ and $\epsilon_{2 t}$, depend explicitly upon the interest rate; $\epsilon_{1 t}$ also depends explicitly upon time. ${ }^{16}$ To remove these sources of heteroscedasticity, we transform equation (21) by multiplying the first equation by $r_{t} / \sqrt{ } t$ and the second by $r_{t}$. Applying the transformations gives

$$
\begin{aligned}
& r_{t} p_{t} / \sqrt{ } t=r_{t} f^{1}\left(x_{1 t}\right) / \sqrt{ } t+v_{1 t} \\
& r_{t} p_{t}^{*}=r_{t} f^{2}\left(x_{2 t}\right)+v_{2 t} .
\end{aligned}
$$


These transformations have the effect of annualizing the prices. These statistical transformations do not alter the interpretations of the parameters.

The errors $\left(v_{1 t}, v_{2 t}\right)$ can now be assumed to be normal random variables independent across time and contemporaneously correlated. Our previous assumptions concerning the $\epsilon$ 's imply that the $v$ 's have mean vector zero and variances $\sigma_{1}^{2}$ and $\sigma_{2 i}^{2}$. The contemporaneous covariance is denoted by $\sigma_{12}$. Each city in the sample is assumed to have a separate variance for land prices (i.e., $\sigma_{12}$ is city specific). Each city also has a different, time varying variance of construction location by virtue of (18).

The parameters of the covariance matrix must be restricted to yield a positive definite matrix. To do this, we express the covariance matrix $\Sigma_{t}$ as the product of a lower triangular matrix $S_{t}$ and its transpose; i.e., $\Sigma_{t}=S_{t} S_{t}^{\prime}$ The matrix $S_{t}$ corresponding to our assumptions concerning $\Sigma_{t}$ is

$$
S_{t}=\left[\begin{array}{cc}
s_{11} & 0 \\
s_{21} & \eta_{0}+\eta_{1} z_{t}^{*}
\end{array}\right] .
$$

The correspondence between $\Sigma_{t}$ and $S_{t} S_{t}^{\prime}$ is not perfect. Specifically, the covariance $\sigma_{12}=s_{11} s_{21}$ varies across urban areas because $s_{11}$ varies across urban areas. Hence the covariance we estimate is slightly more general than $\Sigma_{t}$.

The likelihood function for this model may now be written as

$$
\mathscr{L}=\prod_{t=1}^{T} \frac{\int_{-\infty}^{r_{t}\left(p_{t}-f^{2}\left(x_{2}\right)\right)} n\left(r_{t}\left(p_{t}-f^{1}\left(x_{1 t}\right)\right) / \sqrt{ } t, v_{2 t}\right) d v_{2} t}{\Phi\left[\frac{r_{t}\left(f^{2}\left(x_{2 t}\right)-f^{1}\left(x_{1 t}\right) / \sqrt{ } t\right)}{\sigma_{t}}\right]}
$$

where $n$ is the bivariate normal density function, $\Phi$ is the cumulative normal distribution function, and $\sigma_{t}^{2}=\sigma_{1 t}^{2}+\sigma_{2 t}^{2}-2 \sigma_{12 t}$. The denominator of each term in the likelihood gives the probability of observing a sale in that period.

The maximum likelihood estimates of the parameters of equations (15) and (20) and the covariance parameters are obtained by numerically maximizing $\mathscr{L}$ with respect to these parameters. The estimates are presented in section 4 , after we discuss our data set.

\section{The data set $^{17}$}

The model is estimated using a cross-sectional time series data set for sixteen Census Metropolitan Areas (CMAs) in Canada covering the years 1969 to 1985 . The primary data series is a total selling price index for new housing. ${ }^{18}$ This series gives a quality corrected index based on a monthly survey of major contractors. This series is deflated by the implicit price deflator for gross national expenditure (GNE) to obtain the real price of new housing. The GNE price deflator is used in all conversions to real values and as our measure of inflation.

The time series on prices are not of the same length for each CMA. Since we wish to uncover the parameters of a stochastic process, it is imperative that we retain as much time 
depth as possible. Therefore, the maximum likelihood (ML) estimation is structured to use all the available data for each CMA. The resulting data set contains 191 observations or, approximately, 12 observations per cross section. It should be noted that it is this limited number of observations across time for each city that precludes treating each CMA separately.

\subsection{Construction cost}

The price index for newly completed single detached dwellings includes the price of raw, undeveloped land, the servicing costs associated with bringing the land on-stream for construction, and the material and labor costs of constructing new units. The conversion cost term, $c_{t}$, in equation (20) should be interpreted as including the latter two cost categories. None of the available Canadian construction cost indices corresponds precisely to this definition. The closest we are able to come to this definition is the implicit price deflator for residential construction for Canada. ${ }^{19}$ We use the real value of this index as our measure of $c_{t}$.

\subsection{User cost of capital}

Our user cost of capital variable is based on the chartered bank rate on prime business loans. Normally, one would subtract the expected rate of price inflation from the chartered bank rate to obtain the expected real user cost of capital. Our previous study (Capozza and Schwann, 1989) indicated, however, that the nominal and real rates of interest exert significant separate effects on land development. One reason for this is that the tax subsidy to home ownership tends to increase with the inflation rate, bringing down the effective user cost of capital. In this study, we attempt to capture this tax effect by allowing for an incomplete adjustment of the user cost of capital to fluctuations in the expected rate of inflation. That is, we model $r_{t}$ by

$$
r_{t}=\hat{r}_{t}-\xi i_{t}
$$

where $\hat{r}_{t}$ is the nominal interest rate and $i_{t}$ is the expected rate of price inflation. The coefficient $\xi$ is estimated as an extra parameter in the model, and it gives the degree of adjustment of the user cost of capital to the inflation rate. If $\xi=1$, there is complete adjustment, while if $0 \leq \xi<1$ there is incomplete adjustment. We expect the latter.

In the preceding calculation, the expected rate of inflation is taken as the predicted value from an ARIMA $(1,1,1)$ model of the rate of inflation computed from the GNE price deflator.

\subsection{Other data}

The remaining data in the model are in the city size equation (19). We have already described the vacancy rate and starts ratio data. ${ }^{20}$ The remaining variable is the number of households in each CMA. This series is derived from the household counts from the quinquennial censuses of Canada. The intercensal years were filled in by quadratic interpolation. 


\section{Results}

Our results are presented in tables 1 and 2. Table 1 contains the ML parameter estimates for the land price equation. It also contains iteratively reweighted least squares (WLS) estimates of these parameters. The WLS estimates are inconsistent. They are included to assess the effect of ignoring the truncation problem. Table 2 contains the ML parameter estimates for the hurdle price equation.

\subsection{The price equation}

The first point to note concerning table 1 is that the estimates of the growth rates and standard errors of new housing prices are for groups of urban areas rather than for individual urban areas. We originally estimated the model described above, in which each city was treated separately with respect to $g$ and $\sigma_{1}$, but the information matrix for this model was

Table 1. Land price equation results.

\begin{tabular}{|c|c|c|}
\hline Parameter & $\begin{array}{c}\text { WLS } \\
\text { Estimates } \\
(t)\end{array}$ & $\begin{array}{c}\mathrm{ML} \\
\text { Estimates } \\
(t)\end{array}$ \\
\hline Value of sys. risk, $\lambda b$ & $\begin{array}{r}-.11 \\
(-13.3)\end{array}$ & $\begin{array}{r}-.12 \\
(-9.4)\end{array}$ \\
\hline \multicolumn{3}{|l|}{ Growth rates-gi } \\
\hline Atlantic cities & $\begin{array}{r}-.10 \\
(-12.5)\end{array}$ & $\begin{array}{r}-.11 \\
(-6.3)\end{array}$ \\
\hline Quebec cities & $\begin{array}{r}-.10 \\
(-13.2)\end{array}$ & $\begin{array}{r}-.12 \\
(-10.1)\end{array}$ \\
\hline Ontario cities & $\begin{array}{r}-.10 \\
(-13.1)\end{array}$ & $\begin{array}{r}-.08 \\
(-4.9)\end{array}$ \\
\hline Prairie cities & $\begin{array}{r}-.11 \\
(-13.3)\end{array}$ & $\begin{array}{r}-.09 \\
(-6.4)\end{array}$ \\
\hline B.C. cities & $\begin{array}{r}-.10 \\
(-12.7)\end{array}$ & $\begin{array}{r}-.08 \\
(-2.4)\end{array}$ \\
\hline \multicolumn{3}{|l|}{ Total risk, $\sigma_{1}$} \\
\hline Atlantic cities & .04 & $\begin{array}{r}.02 \\
(5.1)\end{array}$ \\
\hline Quebec cities & .21 & $\begin{array}{r}<.001 \\
(0.2)\end{array}$ \\
\hline Ontario cities & .51 & $\begin{array}{r}.03 \\
(12.6)\end{array}$ \\
\hline Prairie cities & .23 & $\begin{array}{r}.03 \\
(14.0)\end{array}$ \\
\hline B.C. cities & .15 & $\begin{array}{r}.04 \\
(5.2)\end{array}$ \\
\hline Constant $-p_{0}$ & $\begin{array}{r}88.6 \\
(137.6)\end{array}$ & $\begin{array}{c}100 . \\
\text { norm. }\end{array}$ \\
\hline
\end{tabular}

${ }^{1}$ The WLS estimates of the growth rates differ in the third or fourth decimal places.

${ }^{2}$ Normalized for identifiability. 
Table $2 a$. Hurdle price equation results.

\begin{tabular}{lr}
\hline Parameter & $\begin{array}{r}\text { Coefficient } \\
(t)\end{array}$ \\
\hline Constant- $\beta_{\mathbf{0}}$ & 6379.0 \\
& $(71.8)$ \\
Real price of new construction- $\beta_{\mathbf{1}}$ & 196.6 \\
& $(17.3)$ \\
Location rent- $(1-\delta) \psi_{0}^{2}$ & 2.3 \\
& $(2.0)$ \\
City size parameters: & \\
$\quad$ vacancy rate- $\psi_{1}$ & 4.6 \\
& $(12.8)$ \\
starts- $\psi_{2}$ & 31.9 \\
& $(28.6)$ \\
Variance parameters for construction location: & \\
$\quad$ constant- $\eta_{0}$ & 478.6 \\
& $(157.5)$ \\
city size- $-\eta_{1}$ & 2.7 \\
& $(2.9)$ \\
Covariance parameter $-\sigma_{12}$ & -332.5 \\
Inflation adjustment- $\xi$ & $(76.3)$ \\
& .76 \\
\hline
\end{tabular}

Table $2 b$. Derived hurdle price parameters.

\begin{tabular}{lr}
\hline Parameter & $\begin{array}{r}\text { Coefficient } \\
(t)\end{array}$ \\
\hline $\begin{array}{c}\text { City size variance parameters: } \\
\text { constant }-\gamma_{\mathbf{0}}\end{array}$ & 229087. \\
& $(78.7)$ \\
linear term- $\gamma_{1}$ & 2541.1 \\
& $(2.9)$ \\
quadratic term- $-\gamma_{2}$ & 7.0 \\
& $(1.4)$ \\
Correlations: & -.56 \\
Atlantic cities & $(-110.3)$ \\
& -.56 \\
Quebec cities & $(-56.9)$ \\
& -.54 \\
Ontario cities & $(-104.1)$ \\
Prairie cities & -.56 \\
B.C. cities & $(-90.1)$ \\
& -.55 \\
\hline
\end{tabular}

singular. The nub of the problem is that, after the temporal variation in the price indices is accounted for, there is insufficient interurban variation in these price indices to enable identification of city specific land price effects. 
In part, this is due to using price indices rather than actual prices, but this should not be overstressed. In larger part, the lack of interurban variation may be a consequence of the economic geography of Canada. The cities in the sample fall within a set of economic regions, and within each region, the cities tend to respond to the same basic long-term economic forces. Also, for the cities in Quebec, there are cultural and legal similarities which lend them similarity. Thus, our inability to separate the cities within each region using a model which focuses on long-run land pricing may be due to the basic commonality of those cities. These reasons motivate our grouping the cities by economic region. ${ }^{21}$

The economic regions of Canada and the urban areas within each group are indicated in table 4 (see Appendix C).

We now turn to the estimates themselves. First, examining the WLS and ML estimates of the parameters in table 1, we see that the two estimation techniques yield apparently similar results for the value of risk and growth rates in real land prices; however, the results are more disparate than their appearance indicates. The mean absolute deviation of the WLS from the ML estimates is only .018 , but this represents a 21 percent deviation from the ML estimates. The difference between the two sets of estimates for the standard errors of the stochastic processes is clear. WLS vastly overstates the standard errors. Since the hurdle price is an increasing function of the standard error, the use of an inflated standard error increases the estimated hurdle price. Thus, the WLS estimates imply later development than is the case. They also imply a lower irreversibility premium in land prices.

These results provide a partial confirmation of the theoretical model. They indicate that observed land prices are truncated from below in an empirically significant manner and that this truncation is consistent with the existence of a hurdle price for land development.

\subsection{Systematic risk, $\lambda b$}

The ML estimate of the value of systematic risk is -.124 and is highly significant. This term is an unidentified mix of the price of risk $\lambda$ and the rent beta $b$. Since the price of risk is presumably positive, the estimated coefficient implies a negative rent beta. Case and Schiller (1989) obtain a similar result. They directly estimate the rent beta for singlefamily homes in Atlanta, Chicago, Dallas, and San Francisco. The rent betas for the first three urban areas are negative: $-.022,-.014$, and -.066 , respectively, while that for San Francisco is .035 . None of these estimates is statistically significant. The Case and Schiller estimates yield an average rent beta of about -.02 . Using this number, we get 6.2 as a rough estimate of the price of risk for our Canadian urban areas. This amounts to 7 percent of the average price of the new houses in our sample.

\subsection{Growth, $g$}

The estimates of the growth rates are all small but statistically significant. They imply about two points per annum decrease in the real price of new housing. The reasons for the decline in real prices are explored in Appendix C. 


\subsection{Total risk, $\sigma$}

The estimates of the standard errors of the stochastic processes are statistically significant, with the exception of the Quebec urban areas. Again using -.02 as an estimate of the rent beta, we are able to back out rough estimates of proportion of unsystematic risk to total risk. Unsystematic risk accounts for 38 percent, 0 percent, 68 percent, 71 percent, and 68 percent of total risk in the five regions, respectively. Since unsystematic risk increases the hurdle price, these figures imply that development takes place at higher prices for a given size urban area in Ontario, the Prairie provinces, and British Columbia than in Quebec or the Atlantic provinces.

The percentages given above are illustrative only, as they are sensitive to the value of the rent beta. Their rank order is invariant with respect to beta, however. Despite their illustrative character, they are sensible. The low percentage of unsystematic risk in the Atlantic provinces ( 38 percent) merely reflects the low level of temporal variation in prices in these cities as indicated by table 4 . Similarly, high percentages of unsystematic risk in the Prairie provinces ( 71 percent) and in British Columbia (68 percent) are reflections of the variability of prices in these regions. We expected these two regions to have more unsystematic risk as both regions have resource extraction economies which are subject to price shocks in world markets. The low level of unsystematic risk ( 0 percent) for Quebec and the high level of unsystematic risk (68 percent) for Ontario are surprising. The result for Quebec might be related to the way development is regulated under that province's codified legal system, but this is conjecture. The Ontario result is unexpected given the highly diversified nature of this province's economy. The Ontario figure is undoubtedly buoyed up by the high variability of prices in Toronto (see table 4). If Toronto were removed from the set of Ontario cities, the level of unsystematic risk in the remaining cities would fall.

\subsection{Hurdle price equation}

We turn now to table $2 \mathrm{a}$. The coefficient on the real price of new construction is positive, as expected, and statistically significant. The coefficient is larger than is needed to account for the effect of construction costs on new house prices.

\subsection{Location of construction}

The next six parameters deal with the location of construction. The location rent, $(1-\delta) \psi_{0}^{2}$, measures the importance of location rent at the average construction location. It is positive and statistically significant. This indicates that the average construction location is inside the city boundary. Just how far the average location is inside the boundary cannot be determined because we cannot disentangle $\delta$ and $\psi_{0}$.

The effects of the apartment vacancy rate and dwelling starts on the rate of land use are given by $\psi_{1}$ and $\psi_{2}$. As expected, starts exert a significant positive effect on the edge of the city. The apartment vacancy rate has an unexpected positive sign, however. It may be that an increase in apartment vacancies reflects a switch in demand from apartments to single detached dwellings. This switch in demand precipitates development and increases land use. 
The parameters $\eta_{0}$ and $\eta_{1}$ from the decomposition of the covariance matrix, $\Sigma_{t}=S_{t} S_{t}^{\prime}$, are positive and statistically significant. The significance of the city size parameter, $\eta_{1}$, supports our contention that the spread of construction locations is positively related to city size. The parameters of the variance of construction location derived from $\eta_{0}$ and $\eta_{1}$ are presented in table $2 \mathrm{~b}$. They show that the variance increases linearly with city size but not quadratically, as the coefficient $\gamma_{2}$ is insignificant.

The covariance parameter $\sigma_{12}$ is negative and significant. The further construction is from the CBD, the lower is the price of land. Thus, errors in the location of construction affect land prices in a theoretically consistent fashion. To assess the quantitative importance of this relationship, we calculate the correlations between construction location and land prices for each of the city groups. They are reported in table $2 \mathrm{~b}$. The correlations are strong, about .55 in all regions, and they are highly significant. These results support our treatment of the location of construction as a random variable.

The user cost inflation adjustment parameter, $\xi$, is significantly less than unity and, hence, conforms to our expectations.

\subsection{Comparison to earlier results}

In our previous article (Capozza and Schwann, 1989) we were able to establish a significant relationship between the expected rate of urban growth and land prices but unable to establish a statistically significant relationship between housing prices and risk. Our measure of risk in that article was the variance of our measure of expected growth. The problem with this measure is that it is an exogenously imposed measure of price variation. Since risk is measured endogenously in the present model, we avoid this measurement problem. In addition, the much tighter empirical structure of this article enables us to quantify both the net growth premium and the irreversibility premium resulting from the endogenous levels of risk. These premia are calculated for the mean interest rate and mean rate of inflation in the sample period. They are presented in table 3 for the groups of urban areas in our sample.

Because of our negative rent beta, the net growth premia may be interpreted as the increase in housing prices which results from risk-adjusted growth. These premia are all small. The largest statistically significant premium is for urban areas in Ontario, but it amounts to only 1 percent of the housing price.

Table 3. Net growth and irreversibility premia.

\begin{tabular}{llllll}
\hline \multirow{2}{*}{ Parameter } & \multicolumn{5}{c}{ Urban Areas in } \\
\cline { 2 - 6 } Net growth premium & Atlantic & Quebec & Ontario & Prairie & B.C. \\
\hline \multirow{2}{*}{ Irreversibility premium } & .33 & .16 & .95 & .61 & .92 \\
& $(1.7)$ & $(2.1)$ & $(6.3)$ & $(3.8)$ & $(1.6)$ \\
& $.4 \%$ & $.2 \%$ & $1.0 \%$ & $.7 \%$ & $1.2 \%$ \\
& 625.4 & .02 & 51.1 & 19.1 & 4.8 \\
& $(1.0)$ & $(.001)$ & $(26.3)$ & $(10.5)$ & $(.6)$ \\
\hline
\end{tabular}


The irreversibility premia are the option values associated with foregoing future development opportunities by developing the land today. The premiums are statistically significant in two regions: Ontario and the Prairie provinces. In Ontario, the premium represents 53 percent of the value of the housing price, while in the Prairie provinces, it represents 22 percent of the housing price. The premium for the Atlantic urban areas is ridiculously large, albeit statistically insignificant. The actual value results from a very small $\alpha$ at the point of approximation. Letting the real interest rate vary its sample range produces lower estimates of the irreversibility premium; however, the calculated premia remain statistically insignificant. The near zero irreversibility premium for the Quebec cities is a direct result of the low estimated level of total risk in that province. We find the insignificance of the premium result for British Columbia surprising given the high degree of unsystematic risk in that region.

\section{Summary and conclusions}

In this article we have tested the urban asset pricing model of Capozza and Sick (1988) and explored the empirical dimensions of the effects of risk on urban land prices. The effects of systematic and unsystematic risk are distinguished. We find the value of systematic risk in our Canadian urban areas to be negative and highly statistically significant. It is negative because the rent beta linking systematic risk in housing prices to market risk is negative. using $|\lambda b / r|$ as a measure of the systematic risk, we find that approximately 2.5 percent of the value of houses in our sample arises from this source. ${ }^{22}$ This effect is offset in our sample by a negative growth effect, leaving a net growth premium of only 1 percent of the housing price.

In our sample, unsystematic risk tends to be a much larger proportion of total risk than systematic risk. Therefore, most of the effect of total risk may be ascribed to unsystematic risk. The effect of total risk on land prices is illustrated through the irreversibility premia estimates in table 3 . These premia vary greatly in size and statistical significance. Thus, the effect of unsystematic risk is highly city specific. In the two sets of urban areas where the irreversibility premia are statistically significant, it accounts for 22 percent and 53 percent of the average housing price; hence, unsystematic risk can be a very important determinant of housing prices. However, it is clear that further work needs to be done on a city-by-city basis to delineate magnitude of this effect.

We obtain two other notable results. First, our results parallel theory in indicating the importance of location rents. This is shown by the high correlations between the unobserved average location of construction and housing prices. Of necessity, we have dealt with location rents econometrically. It would be preferable to use a sample that contains explicit location measures.

Finally, our results demonstrate the need to account for the endogenous truncation of land prices resulting from the optimizing behavior of developers. We find that ignoring this truncation results in inflated estimates of the hurdle price for development.

\section{Acknowledgments}

This research was initiated while both authors were at the University of British Columbia. The financial support of the Social Sciences and Humanities Research Council of Canada 
and the Real Estate Council of British Columbia is gratefully acknowledged. We thank the three anonymous reviewers for their numerous helpful comments and suggestions.

\section{Notes}

1. For an overview of the empirical literature see Capozza and Schwann (1989).

2. For an overview of the theoretical literature see Capozza and Helsley (1987) and Capozza and Sick (1988).

3. Undeveloped land includes agricultural land and urban undeveloped land.

4. The merits of using the normal diffusion process as opposed to the log-normal diffusion for modelling urban land rents are discussed in Appendix A.

5. We assume that the stochastic process evolves in rents. If rents follow a normal diffusion, land prices will as well (see equation (9)). However, it is possible to derive identical pricing equations by assuming that only prices follow a normal diffusion and rents follow any arbitrary process. To see this notice that in equation (10) the option to convert, $W$, is $W(P(t))$ so that the normal diffusion on rents is not necessary.

6. To avoid carrying excess notation, we omit the time and location arguments when the meaning is clear. $R$ and $P$ should be understood to be $R(z, t)$ and $P(z, t)$, respectively, at all times.

7. See Capozza and Sick (1988) for the details.

8. As $\sigma \rightarrow 0, \alpha \rightarrow r / \hat{g}$ so that $(r-\alpha \hat{g}) /\left(\alpha r^{2}\right) \rightarrow 0$. Therefore, the third term vanishes as $\sigma \rightarrow 0$ and can be viewed as an uncertainty/irreversibility term. Moreover, $r-\alpha \hat{g} \geq 0$, so the third term is nonnegative.

9. See Copeland and Weston (1989) for an overview of the option pricing literature.

10. Time subscripted variables denote observed values.

11. Agricultural economists have estimated land rents as a function of the productive characteristics of the land and other inputs to agricultural production. These estimates are based, in general, on random samples of farms where the samples are taken at irregularly spaced time intervals and the locations of the farms in these samples are only broadly indicated. Thus, we can not draw upon the Canadian agricultural economics literature to obtain estimates of the land rents outside the urban areas in our sample.

12. See Schwann (1989) for a discussion of the optimal scheduling of construction.

13. It is random in the sense that it is unknown by the analyst.

14. In principle, it is possible to include two sets of dummy variables for the cities since the two sets of dummies enter in a nonlinear fashion. However, doing so is still problematic.

15. Clearly, other variables could be introduced into this ad hoc function. We experimented unsuccessfully with a trend variable. The log likelihood function failed to converge when a trend was included as the trend parameter and the parameter $\delta$ oscillated. We interpret this result as indicating a dependence between the number of households in a city and time. This result suggests that in future work the best candidates for inclusion in equation (27) are those with a high degree of temporal variability.

16. The second error also depends upon the size of the city through equation (26). This source of heteroscedasticity can also be removed by a transformation of variables. However, because equation (26) depends on the $\gamma$ parameters, the hurdle price variable would have to be recalculated every time one of these parameters is altered. It is more convenient to address this source of heteroscedasticity through the variance covariance matrix.

17. A detailed description of the data used in this study and its sources is available on request.

18. See Statistics Canada, Construction Price Statistics, Catalogue Number 62-007, for these data and for the residential input price index for Canada described in the next section.

19. A closer set of series are the construction input price indices for the five economic regions of Canada. Unfortunately, these series are not available for the full time span of our study.

20. These data may be found in the Canada Mortgage and Housing Corporation's publication Canadian Housing Statistics, various years.

21. Clearly, other groupings of the cities are possible. Our decision to group by economic region was based, in the first instance, upon a study of the interdependencies within the singular information matrix generated by the city specific model. This study also showed a collinearity between cities of similar size. Since city size is already controlled for in the estimating equation, we decided not to group by this variable.

22. This figure is based on the average user cost of capital of 6.5 percent and the average value of new construction in the cities in our sample of 78.8 index points. 
23. See Capozza and Sick (1988) for the details.

24. As $\sigma \rightarrow 0, \alpha \rightarrow r / \hat{g}$ so that $(r-\alpha \hat{g}) /\left(\alpha r^{2}\right) \rightarrow 0$. Therefore, the third term vanishes as $\sigma \rightarrow 0$ and can be viewed as an uncertainty/irreversibility term. Moreover, $r-\alpha \hat{g} \geq 0$, so the third term is nonnegative.

\section{Appendix A: The Normal Diffusion}

The normal diffusion is a controversial assumption since readers familiar with the literature in finance are accustomed to security prices being assumed to follow a lognormal diffusion, which rules out negative prices. There are a number of reasons why assuming a lognormal diffusion is less compelling in an urban context.

First, in real estate markets negative cash flows (net rents) are common. The normal diffusion admits the possibility of negative cash flows with no additional complication. Indeed, the lognormality assumption for securities is a simplification used to provide a tractable model of limited liability, whereas the limited liability arises from a real put option to abandon a losing business, which is not considered in standard option pricing models. Thus, for tractability it is just as sensible to model the net cash flows as having a normal distribution as a lognormal distribution, since the value of the firm or property is a put option on a claim to these flows. We ignore this put option here, effectively assuming that it has a low value because it is unlikely to be exercised in the near future. In the long run the put option can be exercised, creating lost classical civilizations, for example.

Second, both urban rent and urban price at distances outside the urban boundary are notional because land is still in agricultural use. Because the notional rent is the rent at the center of the urban area adjusted for transport cost, it is clear that if we move arbitrarily far from the center of the urban area these notional rents and prices can become arbitrarily negative. No arbitrage can be made from a negative notional price.

Third, urban land is only available with a complementary product, namely a building. Since these cannot be separated, the package could be priced so low that the land rent is negative, even though no arbitrage is possible. See Mills (1981) on this issue.

Fourth, we believe any stochastic assumption should be viewed as an approximation to reality. Indeed, there is a voluminous and growing literature in finance that considers deviations of stock price movements from lognormal. Ideally one would specify a more general diffusion process that encompasses the normal, lognormal, and others. For example, one could assume that $d R=g R^{\alpha} d t+\sigma \mathrm{R}^{\alpha} d B(t)$ where $\alpha=0$ is normal, and $\alpha=1$ is lognormal. We are unable to obtain closed form solutions using such models and would have to revert to numerical techniques. We believe the loss of intuition from doing so outweighs the gain in generality. We also conjecture that most results will carry through for values of $\alpha$ between zero and one.

Fifth, we have checked the distribution of quarterly housing returns from 1979-1988 for 64 cities in the United States for normality and lognormality. Using a chi-squared test (Kmenta, 1971, pp. 265-267), we find that five cities fail both the normal and the lognormal specification at the 5 percent level. At the 10 percent level seven fail the normal and ten fail the lognormal. Therefore, for the vast majority of cities the normal assumption is consistent with the data and, if anything, is slightly preferable to the lognormal. 
Sixth, there is evidence that urban areas become more stable as they grow because of the diversification of the urban economy. For example, the three largest cities (New York, Los Angeles, Chicago) have an average standard deviation of population growth of 0.2 percent, while the three smallest cities in the 64-city sample (Chattanooga, Lansing, Des Moines) have a standard deviation of 0.6 percent. The normal diffusion is consistent with this empirical regularity while the lognormal is not.

We hope the above is sufficient to convince the reader that the normal diffusion is worth considering. However, in Capozza and Sick (1988), we also provide an analysis using the lognormal diffusion.

\section{Appendix B: Solution}

Urban land effectively pays a dividend at the rate $R d t$. In the absence of arbitrage, the option to convert must satisfy the differential equation,

$$
0=\frac{\sigma^{2}}{2 r^{2}} W_{p p}+(r P-R) W_{p}-r W
$$

This differential equation is subject to two boundary conditions:

$$
P^{*}(t)-A / r-C=W\left(P^{*}(t), t\right)
$$

which states that at conversion the option is worth as much dead as alive, and

$$
W_{p}\left(P^{*}, t\right)=1
$$

which is the Merton-Samuelson high contact condition for $P^{*}$ to be an optimizing policy. $P^{*}$ is the hurdle price at which development occurs.

We also have the boundary condition

$$
W(-\infty, t)=0
$$

This condition states that distant land has no option value. Substituting from equation (7) for $r P-R$ in equation (B1) and applying the boundary conditions yields ${ }^{23}$

$$
\left.W(P(t))=\frac{1}{\alpha r} e^{-\alpha r(P *}-P\right)
$$

and

$$
P^{*}=A / r+C+\frac{\hat{g}}{r^{2}}+\frac{r-\alpha \hat{g}}{\alpha r^{2}}
$$

where 


$$
\alpha=\frac{\left[\hat{g}^{2}+2 r \sigma^{2}\right]^{1 / 2}-\hat{g}}{\sigma^{2}}
$$

and $\hat{g}=g-\lambda b$ is the risk-adjusted growth rate. From equation (B6) it can be seen that the hurdle price $P^{*}$ is composed of the value of pure agricultural land, $A / r$, the cost of conversion, $C$, a growth premium, $g / r^{2}$, and an irreversibility term, $1 /(\alpha r)$.

Substituting the hurdle price, $P^{*}$, into equation (7) defines the hurdle rent, $R^{*}=r P^{*}$ - $\hat{g} / r$. By definition, the boundary of the city occurs at the location $z^{*}(t)$ where $R\left(z^{*}, t\right)$ $=R^{*}$. Using equation (3), this location is, $z^{*}(t)=R(0, t)-R^{*}$; therefore, at an arbitrary location $z$ inside the city

$$
R^{*}-R(z, t)=z-z^{*}
$$

This implies, from equation (B4), that

$$
P^{*}-P=(1 / r)\left(z-z^{*}\right)
$$

Using equation (B9), the value of the option on undeveloped land (equation (B5)) can be written as

$$
W(P(t))=\frac{1}{\alpha r} e^{-\alpha\left(z-z^{*}\right)}
$$

or decomposing the righthand side of equation (B10), as

$$
W(P(t))=\frac{\hat{g}}{r^{2}} e^{-\alpha\left(z-z^{*}\right)}+\frac{r-\alpha \hat{g}}{\alpha r^{2}} e^{-\alpha\left(z-z^{*}\right)}, z \geq z^{*}
$$

Combining this equation with (9), we can express the value of the agricultural land by

$$
P^{a}(t)=\frac{A}{r}+\frac{\hat{g}}{r^{2}} e^{-\alpha\left(z-z^{*}\right)}+\frac{r-\alpha \hat{g}}{\alpha r^{2}} e^{-\alpha\left(z-z^{*}\right)}, z \geq z^{*}
$$

The first term here is the value of pure agricultural land; the second and third are, respectively, the risk-adjusted growth and irreversibility premia. ${ }^{24}$ From equations (B6) and (B9) we have the value of urban land

$$
P(t)=A / r+C+\hat{g} / r^{2}+\frac{r-\alpha \hat{g}}{\alpha r^{2}}+(1 / r)\left(z^{*}-z\right), z \leq z^{*}
$$

The first term represents the value of pure agricultural land; the second is the cost of conversion; the third is the value of net or risk-adjusted growth (which may be negative); the fourth is the irreversibility premium (which is always positive); and the last is the accessibility premium.

Equations (B12) and (B13) are illustrated in figure 1. 
Table 4. Summary statistics: real price of housing, $R P H$.

\begin{tabular}{|c|c|c|c|}
\hline Region & $\Delta R P H_{t}=R P$ & $\triangle R P H_{t}$ & $\begin{array}{c}\text { Std. } \\
\Delta R P H_{t}\end{array}$ \\
\hline \multirow[t]{2}{*}{ Atlantic } & Halifax & -4.9 & 2.2 \\
\hline & St. John's & -2.8 & 4.4 \\
\hline \multirow[t]{2}{*}{ Quebec } & Montreal & 1.4 & 6.9 \\
\hline & Quebec City & -0.5 & 2.3 \\
\hline \multirow[t]{6}{*}{ Ontario } & Hamilton & -2.4 & 2.9 \\
\hline & Kitchener & -2.3 & 3.4 \\
\hline & London & -2.5 & 2.3 \\
\hline & Ottawa-Hull & 0.3 & 6.1 \\
\hline & Toronto & -5.6 & 24.9 \\
\hline & Windsor & -2.6 & 6.6 \\
\hline \multirow[t]{5}{*}{ Prairie } & Calgary & 0.3 & 6.9 \\
\hline & Edmonton & -0.3 & 6.5 \\
\hline & Regina & -3.4 & 2.4 \\
\hline & Saskatoon & -3.1 & 2.0 \\
\hline & Winnipeg & -3.9 & 14.9 \\
\hline B.C. & Vancouver & -5.5 & 8.5 \\
\hline
\end{tabular}

Note: $R P H_{t}$ is the real price of new housing described in the text.

\section{Appendix C: Real New House Prices}

Table 4 gives summary statistics for the year-to-year changes in the real price of new housing index - the variable in which we are primarily interested. The average growth in real new housing prices is negative for most of the urban areas in our sample. On average, the decline was 2.1 points per year. This is slightly greater (in absolute value) than the growth rates estimated for our regional aggregations of urban areas. There is considerable variation among the urban areas, however. The standard error of the variation between urban areas is 2.12 points per year. As large as this is, it is swamped by the year-to-year variation within each urban area. The standard deviation of the interyear variation is greater than 2.12 for all urban areas except one, and a quick comparison of columns 3 and 4 shows that the average decline in real prices is within two standard deviations of zero for all the urban areas except Halifax. This large standard deviation in the annual rates of change of housing prices is consistent with the results recently reported by Case and Schiller (1989) for four American urban areas.

The decline in real new housing prices is surprising since, for the same urban areas, the Multiple Listing Service (MLS) reports increases in the average real value of resold houses. There are a couple reasons why one should not take the difference between the two sets of price statistics too seriously. First, MLS statistics are poor benchmarks because the composition and the number of dwellings in the sample vary with the number of sales in a period. There is a tendency for the average MLS house to rise in quality over time because of renovations to old dwellings and the addition of new high quality units. Thus, these statistics lack any controls for dwelling quality, and the selectivity of the sample introduces an unknown bias, which may well be positive. It was for these reasons we chose not to use the MLS data as our dependent variable. 
Second, the declining real value of new homes may be due to declining real input costs. This explanation is suggested by our conversion cost measure, which also declines over the time period of our sample. To examine this hypothesis, we have regressed the annual changes in the real price of new houses on the annual changes in our conversion cost measure. The results of these regressions are presented in table 5. These regressions show that, for many of the urban areas, changes in real conversion costs explain a significant amount of the decline in real new housing prices. The constant terms for most of the urban areas are closer to zero than the mean changes in the real price of new housing, reported in table 4. Also, the $R^{2}$ 's are substantial for many of the urban areas. The poor performance of several equations may be attributed, in part, to using a national index for conversion costs rather than an urban area specific input price index.

Table 5. Conversion cost regressions.

\begin{tabular}{|c|c|c|c|c|}
\hline \multirow[b]{2}{*}{ Region } & \multicolumn{4}{|c|}{$R P H_{t}-R P H_{t-1}=\theta_{0}+\theta_{1}\left(c_{t}-c_{t-1}\right)+\nu_{t}$} \\
\hline & City & $\begin{array}{l}\theta_{0} \\
(t)\end{array}$ & $\begin{array}{l}\theta_{1} \\
(t)\end{array}$ & $R^{2}$ \\
\hline \multirow[t]{2}{*}{ Atlantic } & Halifax & $\begin{array}{c}-4.1 \\
(-2.35)\end{array}$ & $\begin{array}{c}0.69 \\
(0.67)\end{array}$ & .18 \\
\hline & St. John's & $\begin{array}{c}-1.08 \\
(-0.72)\end{array}$ & $\begin{array}{c}1.18 \\
(2.05)\end{array}$ & .37 \\
\hline \multirow[t]{2}{*}{ Quebec } & Montreal & $\begin{array}{c}1.49 \\
(0.92)\end{array}$ & $\begin{array}{c}1.14 \\
(2.42)\end{array}$ & .35 \\
\hline & Quebec City & $\begin{array}{c}-0.33 \\
(-0.33)\end{array}$ & $\begin{array}{c}0.09 \\
(0.24)\end{array}$ & .01 \\
\hline \multirow[t]{6}{*}{ Ontario } & Hamilton & $\begin{array}{c}-2.11 \\
(-1.72)\end{array}$ & $\begin{array}{c}0.20 \\
(0.42)\end{array}$ & .02 \\
\hline & Kitchener & $\begin{array}{l}-0.60 \\
(0.05)\end{array}$ & $\begin{array}{c}1.44 \\
(5.60)\end{array}$ & .80 \\
\hline & London & $\begin{array}{c}-1.78 \\
(-2.06)\end{array}$ & $\begin{array}{c}0.53 \\
(1.56)\end{array}$ & .26 \\
\hline & Ottawa-Hull & $\begin{array}{c}-0.05 \\
(-0.04)\end{array}$ & $\begin{array}{c}1.23 \\
(3.58)\end{array}$ & .50 \\
\hline & Toronto & $\begin{array}{c}-6.37 \\
(-1.02)\end{array}$ & $\begin{array}{c}2.58 \\
(1.40)\end{array}$ & .13 \\
\hline & Windsor & $\begin{array}{c}-0.98 \\
(-0.37)\end{array}$ & $\begin{array}{c}1.11 \\
(1.08)\end{array}$ & .14 \\
\hline \multirow[t]{5}{*}{ Prairie } & Calgary & $\begin{array}{c}0.03 \\
(-0.02)\end{array}$ & $\begin{array}{c}0.96 \\
(1.99)\end{array}$ & .22 \\
\hline & Edmonton & $\begin{array}{c}-0.57 \\
(-0.45)\end{array}$ & $\begin{array}{c}1.26 \\
(3.25)\end{array}$ & .43 \\
\hline & Regina & $\begin{array}{c}-3.27 \\
(-3.21)\end{array}$ & $\begin{array}{c}0.29 \\
(0.74)\end{array}$ & .07 \\
\hline & Saskatoon & $\begin{array}{c}-2.18 \\
(-3.49)\end{array}$ & $\begin{array}{c}0.63 \\
(2.60)\end{array}$ & .49 \\
\hline & Winnipeg & $\begin{array}{c}-4.67 \\
(-1.50)\end{array}$ & $\begin{array}{c}2.70 \\
(2.94)\end{array}$ & .40 \\
\hline B.C. & Vancouver & $\begin{array}{c}-0.43 \\
(-0.29)\end{array}$ & $\begin{array}{c}3.47 \\
(6.09)\end{array}$ & .84 \\
\hline
\end{tabular}




\section{References}

Capozza, D.R., and Helsley, R. "The Stochastic City." Journal of Urban Economics (forthcoming, 1990).

Capozza, D.R., and Li, Y. "A Generalized Model of Land Conversion Under Uncertainty." Mimeo, University of Michigan, 1989.

Capozza, D.R., and Schwann, G. "The Asset Approach to Pricing Urban Land: Some Empirical Results." AREUEA Journal 17, 2 (1989), 161-175.

Capozza, D.R., and Sick, G. "Risk and Return in the Land Market." Journal of Finance, (forthcoming) 1988.

Case, K. and Schiller, B. "The Efficiency of the Market for Single-Family Homes." American Economic Review 79 (1989), 125-137.

Copeland, T., and Weston, F. Financial Theory and Corporate Policy. Addison-Wesley, 1989.

Kmenta, J. Elements of Econometrics. New York: Macmillan, 1971.

Maddala, G.S. Limited-dependent and Qualitative Variables in Econometrics. New York: Cambridge University Press, 1983.

Mills, D. "Growth, Speculation, and Sprawl in a Monocentric City." Journal of Urban Economics 10 (1981), $201-226$. Schwann, G.M. “Optimal Production Scheduling in Construction." Mimeo, 1989. 